\title{
CONSERVATIVE MODELLING OF THE MOISTURE AND HEAT TRANSFER IN BUILDING COMPONENTS UNDER ATMOSPHERIC EXCITATION
}

\author{
HANS JANSSEN ${ }^{1}$, BERT BLOCKEN AND JAN CARMELIET ${ }^{2}$ \\ Department of Civil Engineering \\ Laboratory of Building Physics \\ Katholieke Universiteit Leuven \\ Kasteelpark Arenberg 40 \\ 3001 Leuven \\ Belgium
}

\begin{abstract}
While the transfer equations for moisture and heat in building components are currently undergoing standardisation, atmospheric boundary conditions, conservative modelling and numerical efficiency are currently not addressed. In a first part, this paper adds a comprehensive description of those boundary conditions, emphasising wind-driven rain and vapour exchange, the main moisture removal and supply mechanism respectively. In the second part the numerical implementation is tackled, with specific attention to the monotony of the spatial discretisation, and to the mass and energy conservation of the temporal discretisation. Both issues are illustrated with exemplary hygrothermal simulations. Numerical efficiency is treated in two follow-up papers.
\end{abstract}

\section{KEYWORDS}

hygrothermal modelling, numerical simulation, heat and moisture transfer, porous materials, atmospheric boundary conditions, conservative modelling

\begin{tabular}{|c|c|c|c|}
\hline \multicolumn{4}{|c|}{ NOMENCLATURE } \\
\hline $\mathrm{C}$ & specific heat $(\mathrm{J} / \mathrm{kgK})$ & $\mathrm{p}_{\mathrm{c}}$ & capillary pressure $(\mathrm{Pa})$ \\
\hline cf & cloudiness factor (-) & $\mathrm{p}_{\mathrm{v}}$ & vapour pressure $(\mathrm{Pa})$ \\
\hline $\mathrm{CR}$ & precipitation heat exchange $\left(\mathrm{W} / \mathrm{m}^{2}\right)$ & $\mathrm{R}$ & precipitation on surface $\left(\mathrm{kg} / \mathrm{m}^{2} \mathrm{~s}\right)$ \\
\hline$E$ & vapour exchange $\left(\mathrm{kg} / \mathrm{m}^{2} \mathrm{~s}\right)$ & $\mathrm{R}_{\mathrm{h}}$ & horizontal rain $\left(\mathrm{kg} / \mathrm{m}^{2} \mathrm{~s}\right)$ \\
\hline $\mathrm{F}$ & view factor $(-)$ & $\mathrm{R}_{\mathrm{wdr}}$ & wind-driven rain $\left(\mathrm{kg} / \mathrm{m}^{2} \mathrm{~s}\right)$ \\
\hline $\mathbf{g}$ & flow $\left(\mathrm{kg} / \mathrm{m}^{2} \mathrm{~s}\right.$ or $\left.\mathrm{W} / \mathrm{m}^{2}\right)$ & S & radiative heat exchange $\left(\mathrm{W} / \mathrm{m}^{2}\right)$ \\
\hline $\mathrm{H}$ & convective heat exchange $\left(\mathrm{W} / \mathrm{m}^{2}\right)$ & $\mathrm{T}$ & temperature $(K)$ \\
\hline $\mathrm{h}$ & $\begin{array}{l}\text { surface transfer coefficient }\left(\mathrm{kg} / \mathrm{m}^{2} \mathrm{sPa}\right. \\
\left.\text { or } W / \mathrm{m}^{2} \mathrm{~K}\right)\end{array}$ & $\mathrm{t}$ & time $(s)$ \\
\hline $\mathbf{K}$ & permeability $(s)$ for $p_{c}$ gradients & $U$ & reference wind speed $(\mathrm{m} / \mathrm{s})$ \\
\hline
\end{tabular}

\footnotetext{
${ }^{1}$ Author to whom correspondence should be addressed Tel.: +32 163213 45, Fax: +32 163219 80, email: hans.janssen@bwk.kuleuven.be ${ }^{2}$ Also at: Faculty of Building and Architecture, Building Physics Group, Technical University Eindhoven, P.O. Box 513, 5600 MB Eindhoven, The Netherlands
} 
$\mathrm{L}_{\mathrm{v}} \quad$ heat of vaporisation $(\mathrm{J} / \mathrm{kg})$

LE vapour transfer heat exchange $\left(W / m^{2}\right)$

\section{Greek symbols}

$\beta \quad$ slope of building component $\left({ }^{\circ}\right)$

$\gamma \quad$ normalised thermal $\sigma$ derivative $\left(K^{-1}\right)$

$\delta_{v} \quad$ permeability $(s)$ for $p_{v}$ gradients

$\varepsilon \quad$ long-wave emissivity of surface (-)

$\theta \quad$ wind direction ( ${ }^{\circ}$ from North)

sub- $\&$ superscripts

$\begin{array}{ll}\text { a/c } & \text { advective/conductive } \\ \text { m/h } & \text { moisture/heat } \\ \text { i/e } & \text { internal/external } \\ \text { s } & \text { surface value } \\ \text { o//lv } & \text { solids/liquid/vapour }\end{array}$

$$
\begin{array}{ll}
\mathrm{V}_{\text {loc }} & \text { Local wind speed }(\mathrm{m} / \mathrm{s}) \\
\mathrm{w} & \text { total moisture content }\left(\mathrm{kg} / \mathrm{m}^{3}\right)
\end{array}
$$

$\begin{array}{ll}\kappa & \text { solar absorption coefficient }(-) \\ \lambda & \text { thermal conductivity }(\mathrm{W} / \mathrm{mK}) \\ \sigma & \text { surface tension }(\mathrm{N} / \mathrm{m}) \\ \rho & \text { density }\left(\mathrm{kg} / \mathrm{m}^{3}\right) \\ \sigma & \text { Boltzmann constant }\left(\mathrm{W} / \mathrm{m}^{2} \mathrm{~K}^{4}\right) \\ \varphi & \text { orientation ( }{ }^{\circ} \text { from North) }\end{array}$

$\begin{array}{ll}\text { gro/sky } & \text { ground/sky } \\ \text { dir/dif } & \text { direct/diffuse } \\ \text { off } & \text { runoff } \\ \text { sat } & \text { saturation value } \\ \text { T } & \text { transpose }\end{array}$

\section{INTRODUCTION}

Until recently, the vapour-diffusion based Glaser method counted as the standard calculation tool [1] for evaluating the hygrothermal behaviour of building components, but its restrictions - stationary, no liquid transfer, no air transfer, ... - render it only rarely reliably applicable. Presently, the application of numerical simulation models for moisture and heat transfer in building components is becoming increasingly common. Hygrothermal simulations of building components have been applied for evaluation of: the hygric and thermal performances of building components [2-4]; the risk of algae formation and mould growth on exterior and interior surfaces [5,6]; the effect of rain buffering on the occurrence and intensity of runoff on brick facades [7]; the effect of interior moisture buffering on the interior relative humidity [8], ... .

The numerical simulation of moisture and heat transfer inside building components is currently undergoing standardisation [9], which includes a recently developed quality assessment methodology [10]. Both are restricted however to the equations for moisture and heat transfer inside permeable building components: neither comprehensively describe the atmospheric boundary conditions, nor do they go deeply into the accuracy and efficiency of the numerical modelling. These topics are however crucial to obtain a comprehensive, accurate and efficient hygrothermal simulation model for building components under atmospheric excitation:

1. The hygrothermal boundary conditions due to atmospheric excitation form the driving forces for moisture and heat transfer inside building components. The dependability of hygrothermal evaluations of building components can not be guaranteed without a complete and accurate description of these atmospheric phenomena. Notwithstanding, incomplete or simplified formulations are given in [9],[10].

2. The standard temporal discretisation of the commonly used capillary-pressure-based moisture transfer equation may lead to serious mass conservation 
errors, due to the strong variation of the moisture capacity with capillary pressure. A conservative temporal discretisation can be developed by using the mixed form of the moisture transfer equation. Nevertheless, conservative modelling is not taken up in $[9,10]$.

3. The numerical efficiency of a simulation model determines the computational cost of hygrothermal evaluations of building components. More efficient solution algorithms will allow performing faster, more, larger, longer or more precise simulations, boosting the application potential of hygrothermal simulations of building components. Nonetheless, numerical efficiency is not addressed in $[9,10]$.

This paper comprehensively presents a mass and energy conservative model for the simulation of moisture and heat transfer in building components under atmospheric excitation, and hence contributes two important subjects: atmospherical boundary conditions, and mass and energy conservative modelling. Potential measures enhancing the numerical efficiency of the hygrothermal simulation model are described in $[11,12]$.

After concisely reiterating the transfer equations, the first section of this article concentrates on the formulation of the atmospheric boundary conditions, the driving forces for the moisture and heat transfer inside building components. This section will mainly go into the modelling of wind-driven rain and vapour exchange, respectively the key moisture supply and removal mechanism for permeable building components [13]. The second section of this paper concerns the numerical modelling of transfer equations and boundary conditions, with specific attention to the monotony of the spatial discretisation, and the mass and energy conservative formulation of the temporal discretisation.

\section{HEAT AND MOISTURE TRANSFER INSIDE BUILDING COMPONENTS}

The majority of building materials can be considered as open porous media - showing a broad range of pore radii, ranging from $10^{-9}$ to $10^{-2} \mathrm{~m}$ - containing a mixture of water, vapour and air in the pores. All constituents interact but due to the complex pore structure involved, an accurate description on the microscopic level remains rather difficult. Some authors did nevertheless take this level as a starting point for the description of moisture and heat transfer in porous media [14,15]: an averaging approach then yields the macroscopic description. Other authors [16-18] used a phenomological approach, starting directly from the macroscopic point of view. Both approaches yield macroscopic equations for moisture and heat transfer in porous media. The averaging technique does however give more insight in the required assumptions. The phenomenological description has prevailed however, and several models describing moisture and heat transfer in building components have been developed on this basis [19], some of which are now commercially available (Match, WUFI, Delphin, ...) [20-22].

It is generally preferred to assume the moisture transfer driven by gradients in capillary pressure [9], as this quantity forms a true potential. The capillary pressure $p_{c}$ is defined as the pressure difference between the liquid and the gaseous phase:

$$
p_{c}=p_{1}-p_{v+a}
$$

and is hence negative for unsaturated conditions. The absolute value of equation (1) is sometimes used for the definition of capillary pressure $[9,10]$. To maintain the association with physical reality - pore water is under tension - and the equivalence with heat transfer - flow transpires contrary to gradients of the driving potential -, such absolute value is not favourable.

The derivation of the moisture and heat transfer equations in porous building materials can be found in $[9,10,19-22]$, and is not repeated. Under the usual assumptions that:

- no air transfer occurs;

- no liquid transfer due to thermal gradients occurs;

- the effect of gravity is negligible; 
- radiative transfer does not occur;

- moisture storage is independent of temperature;

- the gaseous phase does not contribute markedly to moisture nor heat storage;

- the temperatures remain well below the boiling temperature of water; the resulting transfer equations are $[9,10]$ :

$$
\begin{aligned}
& \frac{\partial \mathrm{w}}{\partial \mathrm{p}_{\mathrm{c}}} \frac{\partial \mathrm{p}_{\mathrm{c}}}{\partial \mathrm{t}}=-\nabla^{\top}\left(\mathbf{g}_{\mathrm{m}, \ell}+\mathbf{g}_{\mathrm{m}, \mathrm{v}}\right) \\
&\left(\mathrm{c}_{0} \rho_{0}+\mathrm{c}_{\ell} \mathrm{w}\right) \frac{\partial \mathrm{T}}{\partial \mathrm{t}}+\left(\mathrm{c}_{\ell} \mathrm{T} \frac{\partial \mathrm{w}}{\partial \mathrm{p}_{\mathrm{c}}}\right) \frac{\partial \mathrm{p}_{\mathrm{c}}}{\partial \mathrm{t}}=-\nabla^{\top}\left(\mathbf{g}_{\mathrm{h}, \mathrm{c}}+\mathbf{g}_{\mathrm{h}, \mathrm{a}}\right) \\
& \mathbf{g}_{\mathrm{m}, \ell}=-\mathbf{K}_{\ell} \nabla \mathrm{p}_{\mathrm{c}} \\
& \mathbf{g}_{\mathrm{m}, \mathrm{v}}=-\frac{\boldsymbol{\delta}_{\mathrm{v}} \mathrm{p}_{\mathrm{v}}}{\rho_{\ell} \mathrm{RT}} \nabla \mathrm{p}_{\mathrm{c}}-\frac{\boldsymbol{\delta}_{\mathrm{v}} \mathrm{p}_{\mathrm{v}}}{\rho_{\ell} \mathrm{RT}^{2}}\left(\rho_{\ell} \mathrm{L}_{\mathrm{v}}+\mathrm{p}_{\mathrm{c}}(\mathrm{T} \gamma-1)\right) \nabla \mathrm{T} \\
& \mathbf{g}_{\mathrm{h}, \mathrm{c}}=-\boldsymbol{\lambda} \nabla \mathrm{T} \\
& \mathbf{g}_{\mathrm{h}, \mathrm{a}}=\left(\mathrm{c}_{\ell} \mathrm{T}\right) \mathbf{g}_{\ell}+\left(\mathrm{c}_{\mathrm{v}} \mathrm{T}+\mathrm{L}_{\mathrm{v}}\right) \mathbf{g}_{\mathrm{v}}
\end{aligned}
$$

All symbols concerning transfer equations and boundary conditions are clarified in the nomenclature section at the start of this paper.

\section{ATMOSPHERIC BOUNDARY CONDITIONS FOR MOISTURE AND HEAT TRANSFER}

\subsection{General formulations}

Whereas the atmospheric boundary conditions form the driving forces for the moisture and heat transfer inside building components, most authors $[9,10,19-22]$ remain incomplete on this topic. A dependable model for simulation of moisture and heat transfer in building components under atmospheric excitation can though not go without a complete and accurate implementation of the hygrothermal boundary conditions.

The moisture balance at an external surface is made up by precipitation $\mathrm{R}$ and vapour exchange $E_{e}$, while the respective heat balance comprises convective $\mathrm{H}_{e}$ and radiative $\mathrm{S}_{\mathrm{e}}$ heat exchange, sensible heat transfer due to precipitation $\mathrm{CR}$ and latent and sensible heat transfer due to vapour exchange $L_{e}$ :

$$
\begin{aligned}
& \mathbf{g}_{\mathbf{m}, \mathbf{e s}}=\left(R+E_{e}\right) \cdot \mathbf{n} \\
& \mathbf{g}_{\mathbf{h}, \mathbf{e s}}=\left(H_{e}+S_{e}+C R+L E_{e}\right) \cdot \mathbf{n}
\end{aligned}
$$

where $\mathbf{n}$ is a unit vector perpendicular to the component's surface. The moisture and heat balances at internal surfaces can be described with:

$$
\begin{aligned}
& \mathbf{g}_{\mathbf{m}, \mathbf{s}}=\left(E_{i}\right) \cdot \mathbf{n} \\
& \mathbf{g}_{\mathbf{h}, \mathbf{s}}=\left(H_{i}+L E_{i}\right) \cdot \mathbf{n}
\end{aligned}
$$

Note that the external surface heat balance explicitly includes radiative heat exchange. At the interior surface, both convective and radiative heat exchange are assumed integrated in a global surface transfer coefficient. Boundary flow terms are assumed positive when increasing the mass or energy content of the simulated component.

Precipitation arriving at a building component's surface is made up by horizontal rain $R_{h}$ and wind-driven rain $\mathrm{R}_{\mathrm{wdr}}$. Horizontal rain is rain through a horizontal plane, wind-driven - or driving - rain is rain that is given a horizontal velocity component by the wind. For general application for all potential slopes of building components, the wind-driven rain is defined as the wind-induced deviation from the standard wind-free catchment of horizontal rain. This implies that wind-driven rain amounts may be negative: a windward edge of a flat roof, for example, may under windy conditions get less rain than the horizontal rain amount:

$$
R=R_{h} \cos (\beta)+R_{w d r}
$$


Horizontal rain data are obtained from climate files. Wind-driven rain data are however generally not available in such files, and are calculated from horizontal rain, wind speed and wind direction by use of the wind-driven rain coefficient.

In building physics, vapour exchange between surfaces and the atmosphere is generally described by means of a surface vapour transfer coefficient $h_{m, e}$ :

$$
E_{e}=h_{m, e}\left(p_{v, e}-p_{v, e s}\right)=h_{m, e}\left(p_{v, e}-p_{v, \text { sat }}\left(T_{e s}\right) \exp \left(\frac{p_{c, e s}}{\rho_{\ell} R_{v} T_{e s}}\right)\right)
$$

In equation (13), the surface vapour pressure $p_{v, \text { es }}$ is calculated from the surface capillary pressure with Kelvin's law. The outside vapour pressure is determined from outside air temperature and relative humidity, both obtained from climate files.

As precipitation and vapour exchange form respectively the major moisture supply and removal mechanisms respectively for permeable building components [13], a more exhaustive description on the wind-driven rain and surface vapour transfer coefficients is presented in the next paragraph.

Similarly, convective heat exchange between surfaces and the atmosphere is generally described by use of a surface heat transfer coefficient $h_{h, e}$ :

$$
H_{e}=h_{h, e}\left(T_{e}-T_{e s}\right)
$$

The radiative heat exchange is composed of the absorbed short-wave radiation and the long-wave radiation exchange between surface, atmosphere and ground:

$$
\mathrm{S}_{\mathrm{e}}=\kappa\left(\mathrm{S}_{\text {dir }}+\mathrm{S}_{\text {dif }}\right)+\sigma \varepsilon\left[\mathrm{F}_{\text {gro }}\left(\mathrm{T}_{\text {gro }}^{4}-\mathrm{T}_{\text {es }}^{4}\right)+\mathrm{F}_{\text {sky }}\left(\mathrm{T}_{\text {sky }}^{4}-\mathrm{T}_{\text {es }}^{4}\right)\right]
$$

The direct and diffuse radiation are obtained from climate files. A solar path calculator [23] is used to project the direct radiation on the building component's surface. Ground surface temperature is taken equal to the air temperature, based on [24,25]. Different models exist for the calculation of sky temperatures: a comparison in [24] indicated that the deviations are not that large. The model presented in this paper applies:

$$
\mathrm{T}_{\text {sky }}=\mathrm{T}_{\mathrm{e}}-\left(23.8-0.2025\left(\mathrm{~T}_{\mathrm{e}}-273.15\right)\right)(1-0.87 \mathrm{cf})
$$

A model relating the cloudiness cf to the short-wave radiation was presented by Kasten and Czeplak [26], but was shown to give erroneous results in [24]. The cloudiness factors are thus adopted from solar radiation measurements [27], which though only allow deriving a year-averaged value.

The sensible heat transfer due to precipitation is calculated as:

$$
\mathrm{CR}=\mathrm{c}_{\ell} \mathrm{T}_{\mathrm{e}} \mathrm{R}
$$

Accepting the rain temperature equal to the air temperature is debatable: [24] did demonstrate though that the inclusion of CP in the surface heat balance had practically no effect on surface temperature.

The latent and sensible heat transfer due to vapour exchange can be described with:

$$
\mathrm{LE}_{\mathrm{e}}=\left(\mathrm{c}_{v} \mathrm{~T}_{\mathrm{es}}+\mathrm{L}_{\mathrm{v}}\right) \mathrm{E}_{\mathrm{e}}
$$

The equilibrium in the moisture and heat balances (8-9) does only hold however for unsaturated external surface conditions. During severe precipitation, the moisture supply to the surface may be larger than the possible absorption by the material. At such moments, the surface moisture content reaches its saturation value, and the excess rainfall drains as runoff over the external surface. During such runoff periods, equation (8) is no longer valid, and instead a fixed capillary pressure is to be imposed (9), which also changes the heat balance (20):

$$
\begin{aligned}
\mathrm{p}_{\mathrm{c}, \mathrm{es}}= & 0 \mathrm{~Pa} \\
\mathbf{g}_{\mathrm{h}, \mathrm{es}}= & \mathrm{H}_{\mathrm{e}}+\mathrm{S}_{\mathrm{e}}+\mathrm{CR}-\mathrm{CR}_{\text {off }}+\mathrm{LE}_{\mathrm{e}} \\
& \mathrm{CR}-\mathrm{CR}_{\text {off }}=\mathrm{c}_{\ell} \rho_{\ell} T_{\mathrm{e}} R-\mathrm{c}_{\ell} \rho_{\ell} T_{\mathrm{es}} R_{\text {off }}
\end{aligned}
$$

Currently, as in other hygrothermal models, the model presented in this paper assumes runoff to disappear from the system, and not to form a moisture load for locations lower 
on the building component's surface. A first effort to the combined modelling of capillary sorption and surface flow is documented in [7].

\subsection{Modelling of wind-driven rain}

Wind-driven rain loads on building components are highly variable in space and time. This is due to the variability of the main influencing parameters: building geometry, environment topography, position on the building, wind speed, wind direction, horizontal rainfall and raindrop-size distribution. Three categories of methods exist for the quantification of wind-driven rain loads: measurements, semi-empirical formulae and numerical simulation methods based on CFD (Computational Fluid Dynamics). A review on each of these methods was recently provided by Blocken and Carmeliet [28]. The methodology that is suggested in this paper is based on the combination of the numerical simulation model for wind-driven rain [29], and the additional insight and simplifications recently provided by Janssen et al. [13].

Wind-driven rain can be calculated with the wind-driven rain relationship:

$$
R_{\text {wdr }}=\alpha\left(R_{h}, U, \theta-\varphi\right) R_{h} U
$$

where $\alpha$ is the wind-driven rain coefficient. Because of the very simple form of (21), the entire complexity of the interaction between wind, rain and building has to be integrated in this coefficient. Resultantly, this coefficient is a complicated function of $R_{h}, U$ and $(\theta-$ $\varphi)$, and CFD is employed to determine this function. A three-step approach is used:

1. Steady-state wind-flow pattern

The steady-state wind-flow pattern around the building is calculated with CFD. The Reynolds-Averaged Navier-Stokes equations are solved with the control volume method and closure is obtained by the use of the realizable k- $\varepsilon$ turbulence model. The result of the calculation procedure is the velocity-vector field around the building.

\section{Raindrop trajectories}

Raindrop trajectories are obtained by injecting raindrops of different sizes in the calculated velocity-vector field and by solving their equations of motion. Drops are injected from a horizontal plane, located in the upstream-undisturbed windflow pattern high above the ground, to allow them to reach their terminal fall velocity (vertical) and wind velocity (horizontal) before entering the flow pattern disturbed by the presence of the building.

3. Specific and integrated catch ratio, and wind-driven rain coefficient Comparing the horizontal raindrop density (injection density) with the density of the wind-driven rain drops arriving at the building facade results in values for the specific catch ratio $R_{w d r}(d) / R_{h}(d)$, for each raindrop diameter $d$. The integrated catch ratio $R_{w d r} / R_{h}$ is obtained by integration of the specific catch ratio's over the raindrop spectrum. Finally, the wind-driven rain coefficient $\alpha$ is acquired by division with the reference wind speed.

For more details, the reader is referred to [29]. The results of this procedure are winddriven rain coefficients for a given building geometry and environment topology, for all positions on the building facades and for different values of wind speed, wind direction and horizontal rainfall intensity. As an example, Figure 1 shows two wind-driven rain coefficient charts, illustrating $\alpha$ as a function of wind speed and horizontal rainfall intensity, for two positions on the windward facade - with the wind perpendicular to the façade - of a cubic $10 \times 10 \times 10 \mathrm{~m}^{3}$ building, located on a grass-covered plain without other nearby obstacles [30].

The resulting wind-driven rain coefficient $\alpha$ is generally a pronounced function of $R_{h}, U$ and $(\theta-\varphi)$. For the purpose of hygrothermal simulations of building components though, Janssen et al. [13] verified that, in most cases, the dependence of $\alpha$ on wind direction 
can be reliably simplified by projecting the wind-velocity vector on the facade's normal, yielding a simplified wind-driven rain relationship:

$$
R_{\text {wdr }}=\alpha_{\perp}\left(R_{h}, U \cdot \cos (\theta-\varphi)\right) R_{h} U \cdot \cos (\theta-\varphi)=\alpha_{\perp}\left(R_{h}, U^{\prime},\right) R_{h} U^{\prime}
$$

where $\alpha_{\perp}$ is the coefficient for a wind direction perpendicular to the facade and $U$ ' is the projection of $U$ on the normal to the facade. On the other hand though, the same study also indicated that the dependence of $\alpha_{\perp}$ on $U$ ' and $R_{h}$ cannot be neglected for reliable hygrothermal simulations, stressing the importance of CFD-based wind-driven rain coefficients for this purpose.

\subsection{Calculation of convective surface transfer coefficients}

The surface moisture and heat transfer coefficients govern the convective exchange of vapour and heat between the atmosphere and a component's outer surface (equations $(13,14))$. Reliable calculation of these is however cumbersome, as comprehensive models are still lacking.

Moisture and heat transfer at external surfaces are dominated by the forced convection due to wind, and thus depend strongly on the local air velocity. While the latter relation has occasionally been measured in wind tunnels [31,32], the relation between the reference wind speed and the local air velocity is still lacking. Like for wind-driven rain, this could be quantified by numerical CFD simulations. Building geometry, environment topography, position on building, wind speed and direction will likewise become important influencing parameters. At present such CFD-based relations are not available though. The surface transfer coefficients furthermore depend on the pore structure, and on the roughness of the external building material [31,32]. Worch [31] furthermore stated that the moisture transfer coefficients depend on the moisture content at the surface. Presently none of these influences has been integrated in models yet.

Due to the lack of reliable and validated models, one has to refer to empirical data for the heat transfer coefficient and to analogies for the moisture transfer coefficient. The heat transfer coefficient can be obtained from large-scale measurements of convective heat transfer at building components' surfaces [19,33-36], which relate a 'building-part averaged' surface heat transfer coefficient to the reference wind speed. Figure 2 illustrates the various relations between the wind speed and surface heat transfer coefficient [33-36]. The expression leading to the most central result [35] is retained:

$$
\begin{aligned}
& \mathrm{h}_{\mathrm{h}, \mathrm{e}}=1.7 \mathrm{~V}_{\text {loc }}+5.1 \\
& \mathrm{~V}_{\text {loc }}=1.8 \mathrm{U}+0.2 \text { (windward) } \quad \mathrm{V}_{\text {loc }}=0.4 \mathrm{U}+1.7 \text { (leeward) }
\end{aligned}
$$

where $V_{\text {loc }}$ is the local air velocity.

For the surface moisture transfer coefficients on the other hand, empirical data are limited [37]. It is therefore commonly preferred to derive them from their thermal counterparts, based on the 'Lewis analogy' [19], which assumes the thermal and hygric boundary layers to be similarly shaped and sized. In that case, the surface moisture transfer coefficient can be assumed proportional to the surface heat transfer coefficient:

$$
\mathrm{h}_{\mathrm{m}, \mathrm{e}}=7.710^{-9} \mathrm{~h}_{\mathrm{h}, \mathrm{e}}
$$

The existence of such proportionality between $h_{h, e}$ and $h_{m, e}$ is supported by the data of Schwarz [37].

Variation of the surface transfer coefficients with building geometry, environment topography, location on the building, structure of material and surface is hence not accounted for in the proposed methodology. Janssen et al. [13] demonstrated though that the surface transfer coefficients significantly affect the moisture transfer in permeable building components: for reliable simulations, accurate hourly values are required. It is obvious that the accepted methodology needs refining, and further research on this matter is strongly encouraged. 


\subsection{Climate data}

Meteorological data are generally gathered as arithmetically averaged values over $10-$ minute intervals, and are then processed to average values over longer time intervals. The use of hourly averaged climate data, instead of original 10-minute data, in simulations of vapour transfer in building components, was analysed by Geving [38]: no substantial deviations were observed. A just as comprehensive analysis of liquid transfer is still lacking. Blocken and Carmeliet [39] state that 10-minute rain intensity and wind speed data are most appropriate for accurate estimations of the wind-driven rain loads, and indicate that the commonly arithmetically averaged hourly $R_{h}$ and $U$ values tend to lead to underestimations. Instead $R_{h}$-weighted hourly averages of $R_{h}$ and $U$ should be used. For moisture and heat transfer simulations, it was confirmed that such weighted averages generally yield equally accurate predictions of longer-term variations of moisture transfer [39]. For shorter-term phenomena like runoff and water penetration however, reliable predictions can only be made with short-term climate data.

The availability of climate files on a 10-minute basis or on an hourly basis including $R_{h}$ weighted $R_{h}$ and $U$ averages is however almost none. Currently ongoing work focuses on the establishment of hourly databases containing weighted-averaged wind and rain data [39], and further efforts in this direction are encouraged. For the meantime though, traditional arithmetically hourly averaged climate values have to be assumed satisfactory.

\section{Conservative NUMERICAL IMPLEMENTATION}

The strongly non-linear transfer equations (2-7) and boundary conditions (8-24), describing the transfers of heat and moisture in building components under atmospheric excitation, defy analytical solution and hence require numerical solution. In the presented model, the finite-element method is favoured for the spatial discretisation, in combination with an implicit finite-difference scheme for the temporal discretisation. In this development, specific attention is paid to the effect of the spatial discretisation on the monotony of the solution, to the influence of the temporal discretisation on mass and energy conservation and to the linearisation technique. Whereas of major importance to attain an accurate - and efficient - hygrothermal simulation model, these topics are not tackled in [9,10,19-22].

\subsection{Spatial and temporal discretisation}

The transfer equations (2-7) can be represented as:

$$
\begin{aligned}
& \mathrm{c}_{\mathrm{mm}} \frac{\partial \mathrm{p}_{\mathrm{c}}}{\partial \mathrm{t}}+\mathrm{c}_{\mathrm{mh}} \frac{\partial \mathrm{T}}{\partial \mathrm{t}}-\nabla^{\mathbf{T}}\left(\mathrm{k}_{\mathrm{mm}} \nabla \mathrm{p}_{\mathrm{c}}+\mathrm{k}_{\mathrm{mh}} \nabla \mathrm{T}\right)=0 \\
& \mathrm{c}_{\mathrm{hh}} \frac{\partial \mathrm{T}}{\partial \mathrm{t}}+\mathrm{c}_{\mathrm{hm}} \frac{\partial \mathrm{p}_{\mathrm{c}}}{\partial \mathrm{t}}-\nabla^{\mathbf{T}}\left(\mathrm{k}_{\mathrm{hh}} \nabla \mathbf{T}+\mathrm{k}_{\mathrm{hm}} \nabla \mathrm{p}_{\mathrm{c}}\right)=0
\end{aligned}
$$

Spatial discretisation. The Galerkin weighted-residual finite-element method, instead of finite-difference or control-volume methods, is favoured for the spatial discretisation of equations (25-26). The finite-element technique explicitly assumes a variation of the independent variables over the calculation domain, which is considered numerically superior. Moreover, surface values of the capillary pressure and temperature are required for the evaluation of the boundary conditions. These are only directly available for the finite-element method, while necessitating additional approximation in the finite-difference and control-volume methods. The following elaboration is limited to the moisture transfer equation. The weak Galerkin formulation and Green-Gauss theorem convert (25) into: 


$$
\begin{gathered}
\int_{\Omega}\left[\mathrm{Mc}_{\mathrm{mm}} \frac{\partial \mathrm{p}_{\mathrm{c}}}{\partial \mathrm{t}}+\mathrm{Mc}_{\mathrm{mh}} \frac{\partial \mathrm{T}}{\partial \mathrm{t}}+\nabla^{\top} \mathrm{M}\left(\mathrm{k}_{\mathrm{mm}} \nabla \mathrm{p}_{\mathrm{c}}+\mathrm{k}_{\mathrm{mh}} \nabla \mathrm{T}\right)\right] \mathrm{d} \Omega \\
-\oint_{\Gamma} \mathrm{Mn}^{\top}\left(\mathrm{k}_{\mathrm{mm}} \nabla \mathrm{p}_{\mathrm{c}}+\mathrm{k}_{\mathrm{mh}} \nabla \mathrm{T}\right) \mathrm{d} \Gamma=0
\end{gathered}
$$

where $\Omega$ is the spatial domain under consideration, $\mathrm{M}$ a weight function and $\mathbf{n}$ is a unit vector perpendicular to the boundary $\Gamma$ of the calculation domain. For practical applicability, the calculation domain $\Omega$ is subdivided into a number of small elements $\Omega^{\mathrm{e}}$. Within each element, the unknown $p_{c}(x, y, z)$ and $T(x, y, z)$ are approximated with shape functions between the nodal values:

$$
\begin{aligned}
\mathbf{p}_{\mathrm{c}} & =\mathbf{N} \mathbf{p}_{\mathrm{c}}^{\mathrm{e}} \\
\mathrm{T} & =\mathbf{N} \mathbf{T}^{\mathrm{e}}
\end{aligned}
$$

where $\mathbf{N}$ contains the shape functions and $\mathbf{p}_{\mathrm{c}}{ }^{\mathrm{e}}$ and $\mathbf{T}^{\mathrm{e}}$ contain the nodal values of the capillary pressure and temperature. By choosing the weight functions $\mathrm{M}$ equal to the shape functions $\mathrm{N}$, the resulting set of equations for each element can be rewritten in matrix form as:

$$
\begin{aligned}
& \mathbf{C}_{\mathrm{mm}}^{\mathbf{e}} \frac{\partial \mathbf{p}_{\mathrm{c}}^{\mathrm{e}}}{\partial \mathrm{t}}+\mathbf{C}_{\mathrm{mh}}^{\mathbf{e}} \frac{\partial \mathbf{T}^{\mathbf{e}}}{\partial \mathrm{t}}+\mathbf{K}_{\mathrm{mm}}^{\mathbf{e}} \mathbf{p}_{\mathrm{c}}^{\mathbf{e}}+\mathbf{K}_{\mathrm{mh}}^{\mathbf{e}} \mathbf{T}^{\mathbf{e}}=\mathbf{F}_{\mathrm{m}}^{\mathbf{e}} \\
& \mathrm{C}_{\mathrm{mm}, \mathrm{ij}}^{\mathrm{e}}=\int_{\Omega^{\mathrm{e}}} \mathrm{C}_{\mathrm{mm}} \mathrm{N}_{\mathrm{i}} \mathrm{N}_{\mathrm{j}} \mathrm{d} \Omega \quad \mathrm{C}_{\mathrm{mh}, \mathrm{ij}}^{\mathrm{e}}=\int_{\Omega^{\mathrm{e}}} \mathrm{C}_{\mathrm{mh}} \mathrm{N}_{\mathrm{i}} \mathrm{N}_{\mathrm{j}} \mathrm{d} \Omega \\
& \mathrm{K}_{\mathrm{mm}, \mathrm{ij}}^{\mathrm{e}}=\int_{\Omega^{\mathrm{e}}} \mathrm{k}_{\mathrm{mm}} \nabla^{\top} \mathrm{N}_{\mathrm{i}} \nabla \mathrm{N}_{\mathrm{j}} \mathrm{d} \Omega \quad \mathrm{K}_{\mathrm{mh}, \mathrm{j}}^{\mathrm{e}}=\int_{\Omega^{\mathrm{e}}} \mathrm{k}_{\mathrm{mh}} \nabla^{\top} \mathrm{N}_{\mathrm{i}} \nabla \mathrm{N}_{\mathrm{j}} \mathrm{d} \Omega \\
& \mathrm{F}_{\mathrm{m}, \mathrm{i}}^{\mathrm{e}}=\int_{\Gamma^{\mathrm{e}}} \mathrm{N}_{\mathrm{i}} \mathrm{g}_{\mathrm{m}, \mathrm{n}} \mathrm{d} \Gamma
\end{aligned}
$$

where $\mathbf{C}^{\mathrm{e}}{ }_{\mathrm{xx}}$ are the element capacity matrices, $\mathbf{K}_{\mathrm{xx}}^{\mathrm{e}}$ the element permeability matrices, $\mathbf{F}^{\mathrm{e}}{ }_{\mathrm{x}}$ the element external load vector and $\mathrm{g}_{\mathrm{x}, \mathrm{n}}$ is the external load, normal to the boundary. At this point, boundary conditions (7-24) can be inserted. While finite-difference and control-volume discretisations assign one storage capacity to a zone surrounding a node, and require an assumption on the average permeability between neighbouring nodes [40], the finite-element method yields an unambiguous treatment of the capacity and permeability terms (30.1-2). The integrals (30.1-3) are calculated numerically, applying Gauss-Legendre numerical integration formulae. Assemblage of the equations over the complete calculation domain yields (for moisture and heat transfer equation):

$$
\begin{aligned}
& \mathbf{C}_{\mathrm{mm}} \frac{\partial \mathbf{p}_{\mathrm{c}}}{\partial \mathrm{t}}+\mathbf{C}_{\mathrm{mh}} \frac{\partial \mathbf{T}}{\partial \mathrm{t}}+\mathbf{K}_{\mathrm{mm}} \mathbf{p}_{\mathrm{c}}+\mathbf{K}_{\mathrm{mh}} \mathbf{T}=\mathbf{F}_{\mathrm{m}} \\
& \mathbf{C}_{\mathrm{hh}} \frac{\partial \mathbf{T}}{\partial \mathrm{t}}+\mathbf{C}_{\mathrm{hm}} \frac{\partial \mathbf{p}_{\mathrm{c}}}{\partial \mathrm{t}}+\mathbf{K}_{\mathrm{hh}} \mathbf{T}+\mathbf{K}_{\mathrm{hm}} \mathbf{p}_{\mathrm{c}}=\mathbf{F}_{\mathrm{h}}
\end{aligned}
$$

where $\mathbf{C}_{\mathbf{x x}}$ are the global capacity matrices, $\mathbf{K}_{\mathbf{x x}}$ the global permeability matrices and $\mathbf{F}_{\mathbf{x x}}$ the global external load vectors. The system of equations (31-32) can generally be represented as:

$$
\mathbf{C} \frac{\partial \mathbf{U}}{\partial \mathrm{t}}+\mathbf{K U}=\mathbf{F}
$$

where $\mathbf{U}$ represents the unknown nodal values for one or both of the independent variables, and $\mathbf{C}, \mathbf{K}$ and $\mathbf{F}$ are composed from the different $\mathbf{C}_{\mathrm{xx}}, \mathbf{K}_{\mathrm{xx}}$ and $\mathbf{F}_{\mathrm{x}}$.

Temporal discretisation. To transform the system of differential equations (34) into algebraic equations, an appropriate temporal discretisation needs to be applied. The so called $\theta$-family of finite-difference schemes is a commonly used method: 


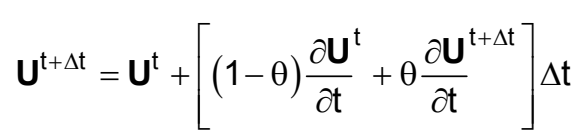

where $\theta$ is a parameter limited to $[0,1]$, and $t$ and $\Delta t$ are the current time and time step (s) respectively. The conditionally stable explicit scheme $-\theta$ equal to $0-$ is not preferable, as it results in slow simulations: the necessarily small spatial discretisation to describe sharp moisture fronts in free water uptake experiments severely limits the time step size. The unconditionally stable Crank-Nicholson and implicit algorithms $-\theta$ equal to 0.5 and 1 respectively - on the other hand do not impose such limits: the larger time steps will easily compensate the required iterative solution of the non-linear equations and matrix inversions. The stable Crank-Nicholson can though not avoid oscillatory solutions [41]. Patankar [41] moreover reasons that the implicit algorithm is closer to reality. Van Genuchten [42] furthermore states that the implicit solution is more efficient, except when very strict accuracy limits are enforced. An implicit algorithm is moreover desirable when the storage terms are (near) zero and equation (33) becomes an elliptic equation [43]. The example section at the end of the paper will confirm that such fully implicit temporal discretisation does not introduce any significant deviations. Inserting equation (34) in (33) converts the differential equations to algebraic equations:

$$
\left(\mathbf{C}^{\mathrm{t}+\Delta \mathrm{t}}+\Delta \mathrm{t} \mathbf{K}^{\mathrm{t}+\Delta \mathrm{t}}\right) \mathbf{U}^{\mathrm{t}+\Delta \mathrm{t}}=\mathbf{F}^{\mathrm{t}+\Delta \mathrm{t}} \Delta \mathrm{t}+\mathbf{C}^{\mathrm{t}+\Delta \mathrm{t}} \mathbf{U}^{\mathrm{t}}
$$

\subsection{Monotony considerations}

Several authors [43]-[46] indicate that the spatial discretisation of the moisture transfer equation with the finite-element method may lead to non-smooth, oscillatory solutions, particularly when simulating free water uptake into dry porous materials. The resulting over- and undershoots at the toe of the moisture fronts become more serious for lower initial moisture contents and for larger grid spacings. These oscillations are generally attributed to the mass distribution in the capacity matrices (30.1), characteristic to the finite-element method. Finite-difference or control-volume discretisations on the other hand, leading to diagonal - or lumped - capacity matrices, do not demonstrate such non-monotone behaviour [46]. Pan et al. [47] showed that the finite-element method may lead to negative "neighbouring node responses" - resulting in an unphysical decrease in moisture content as response to a positive inflow - when the moisture content increase in the neighbouring nodes is very large, such as at a sharp wetting front. The common measure to eliminate the unphysical oscillations is mass lumping. Neumann [43] proposed to replace the matrices (30.1) by their lumped variants:

$$
\mathrm{C}_{\mathrm{mm}, \mathrm{ij}}^{\mathrm{e}}=\delta_{\mathrm{ij}} \int_{\Omega^{\mathrm{e}}} \mathrm{C}_{\mathrm{mm}} \mathrm{N}_{\mathrm{i}} \mathrm{d} \Omega
$$

where $\delta_{i j}$ is the Kronecker delta. (36) is equivalent to shifting the off-diagonal elements in (30.1) onto the diagonal. Several authors have reported to obtain non-oscillatory results with (36), but all applied mass lumping combined only with linear shape functions [43-46]. When implemented lumping indeed removed the oscillations, but only if linear elements were used. With higher-order shape functions, the over- and undershoot remained. This observation indicates that equation (36) may not be generally applicable, which was also stated by Reddy and Gartling [48]. Given this lack of general validity, it is therefore decided not to apply mass lumping.

Oscillations at the toe of the moisture front mostly occur when simulating free water uptake experiments with rough spatial and temporal discretisations. In the example section closing this paper, it will be shown that their influence on the results is minimal. Simulations under atmospheric excitation, on the other hand, will only very rarely develop the conditions necessary for such sharp moisture fronts, and will thus not be considerably affected by maintaining the consistent, mass distributed capacity matrices (30.1). 


\subsection{Mass and energy conservative modelling}

For reasons of clarity, the development of a conservative transfer equation will first be restricted to isothermal liquid water transfer. The introduced principles are afterwards extended to the coupled transfer of moisture and heat.

Isothermal liquid transfer. As mentioned before, moisture transfer is rather described based on capillary pressure, as this quantity forms a true potential for moisture transfer:

$$
\frac{\partial \mathrm{w}}{\partial \mathrm{p}_{\mathrm{c}}} \frac{\partial \mathrm{p}_{\mathrm{c}}}{\partial \mathrm{t}}-\nabla^{\mathbf{T}}\left(\mathbf{K}_{\ell} \nabla \mathrm{p}_{\mathrm{c}}\right)=0
$$

Several authors report unacceptably large mass conservation errors though, independent of the spatial discretisation method [44-46]. Equation (38) on the other hand, based on the moisture content as flow potential, is unconditionally mass conserving:

$$
\frac{\partial \mathrm{w}}{\partial \mathrm{t}}-\nabla^{\mathbf{T}}\left(\mathbf{D}_{\ell} \nabla \mathbf{w}\right)=0
$$

where $D_{\ell}$ is the moisture diffusivity $\left(\mathrm{m}^{2} / \mathrm{s}\right)$.

These mass conservation errors must arise from the non-linear nature of equation (37): the storage coefficient $\partial w / \partial p_{c}$ depends strongly on the capillary pressure $p_{c}$ (Figure 3 ). Its time-discrete evaluation - be it at $t, t+\Delta t, t+\Delta t / 2$ - can never be entirely representative for the storage process over the complete time interval from $t$ to $t+\Delta t$, as $\partial w / \partial p_{c}$ varies continuously with the evolution from $p_{c}{ }^{t}$ to $p_{c}{ }^{t+\Delta t}$. Celia et al. [46] therefore introduced the mixed form. With a finite-difference temporal discretisation this becomes:

$$
\frac{\partial \mathrm{w}}{\partial \mathrm{t}}-\nabla^{\mathbf{T}}\left(\mathbf{K}_{\ell} \nabla \mathrm{p}_{\mathrm{c}}\right)=\frac{\mathrm{w}^{\mathrm{t}+\Delta \mathrm{t}}-\mathrm{w}^{\mathrm{t}}}{\Delta \mathrm{t}}-\nabla^{\mathbf{T}}\left(\mathbf{K}_{\ell} \nabla \mathrm{p}_{\mathrm{c}}\right)=0
$$

An iterative solution procedure is needed for the non-linear equation (39), in which the value of $w$ after iteration $m+1$ in the $t$ to $t+\Delta t$ time step $\left(w^{t+\Delta t, m+1}\right)$ can be estimated with a truncated Taylor series:

$$
\underbrace{\left.\frac{\partial \mathrm{w}}{\partial \mathrm{p}_{\mathrm{c}}}\right|^{\mathrm{t}+\Delta t, \mathrm{~m}}\left(\mathrm{p}_{\mathrm{c}}^{\mathrm{t}+\Delta t, \mathrm{~m}+1}-\mathrm{p}_{\mathrm{c}}^{\mathrm{t}+\Delta \mathrm{t}, \mathrm{m}}\right)}_{\mathrm{A}}+\underbrace{\left(\mathrm{w}^{\mathrm{t}+\Delta \mathrm{t}, \mathrm{m}}-\mathrm{w}^{\mathrm{t}}\right)}_{\mathrm{B}}-\nabla^{\mathbf{T}}\left(\mathbf{K}_{\ell} \nabla \mathrm{p}_{\mathrm{c}}\right) \Delta \mathrm{t}=0
$$

An equivalent form of the original $p_{c}$-based moisture transfer equation (37) is:

$$
\underbrace{\left.\frac{\partial \mathrm{w}}{\partial \mathrm{p}_{\mathrm{c}}}\right|^{\mathrm{t}+\Delta \mathrm{t}, \mathrm{m}}\left(\mathrm{p}_{\mathrm{c}}^{\mathrm{t}+\Delta \mathrm{t}, \mathrm{m}+1}-\mathrm{p}_{\mathrm{c}}^{\mathrm{t}}\right)}_{\mathrm{C}}-\nabla^{\mathbf{T}}\left(\mathbf{K}_{\ell} \nabla \mathrm{p}_{\mathrm{c}}\right) \Delta \mathrm{t}=0
$$

The mass storage in the mixed (40) and $p_{c}$-based (41) moisture transfer equations is illustrated in Figure 3 . This comparison reveals the mass conserving properties of the mixed formulation. When convergence is near, $p_{c}{ }^{t+\Delta t, m+1}$ and $p_{c}{ }^{t+\Delta t, m}$ are almost equal, and the exact value of the capacity term $\partial \mathrm{w} / \partial \mathrm{p}_{\mathrm{c}}$ is no longer important: the storage of moisture is defined by $w^{t+\Delta t, m}-w^{t}$, leading to a mass-conserving mixed equation (40). This is not the case though for the $p_{c}$-based equation (41), where $\partial w / \partial p_{c}$ completely determines the storage of mass and leads to faulty estimates.

Coupled moisture and heat transfer. The principles put forward originally for isothermal liquid water transfer [46] can be easily extended to the coupled transfer of moisture and heat, yielding a mass and energy conservative scheme [24]:

$$
\begin{gathered}
\left(\mathbf{C}^{\mathrm{t}+\Delta \mathrm{t}, \mathrm{m}}+\Delta \mathrm{t} \mathbf{K}^{\mathrm{t}+\Delta \mathrm{t}, \mathrm{m}}\right) \mathbf{U}^{\mathrm{t}+\Delta \mathrm{t}, \mathrm{m}+1}=\Delta \mathrm{t} \mathbf{F}^{\mathrm{t}+\Delta \mathrm{t}, \mathrm{m}}+\mathbf{C}^{\mathrm{t}+\Delta \mathrm{t}, \mathrm{m}} \mathbf{U}^{\mathrm{t}+\Delta t, \mathrm{~m}}-\left(\mathbf{S}^{\mathrm{t}+\Delta \mathrm{t}, \mathrm{m}}-\mathbf{S}^{\mathrm{t}}\right) \\
\mathrm{S}_{\mathrm{m}, \mathrm{i}}^{\mathrm{e}}=\int_{\Omega^{\mathrm{e}}} \mathrm{wN}_{\mathrm{i}} \mathrm{d} \Omega \quad \mathrm{S}_{\mathrm{h}, \mathrm{i}}^{\mathrm{e}}=\int_{\Omega^{\mathrm{e}}} \mathrm{T}\left(\mathrm{c}_{0} \rho_{0}+\mathrm{c}_{\ell} \mathrm{w}\right) \mathrm{N}_{\mathrm{i}} \mathrm{d} \Omega
\end{gathered}
$$

The application of the conservative formulation (42) does not require more computatio- 
nal effort. Its relevance is illustrated in the example section concluding this paper. As is evident from the description above, the mass and energy conservative modelling is independent of the spatial discretisation method and can thus be generally applied. It has though not been implemented in any of the currently available hygrothermal simulation models [9,10,19-22].

\subsection{Linearisation techniques}

The resulting system of equations is non-linear as the capacity, permeability and load matrices all depend on the unknown capillary pressures and temperatures, and has thus to be iteratively linearised to allow solution.

Picard iterative scheme. The Picard iterative scheme (42) applies substitution: C, K and $\mathbf{F}$ are calculated with capillary pressures and temperatures from the previous iteration and an iterative loop is continued till convergence. The Picard scheme is straightforward but rather inefficient: primarily for the non-linear boundary conditions governed by transfer coefficients (the vapour exchange (13) is by far the best example), convergence is poor, and long calculation times arise. Poor convergence on flux-type boundary conditions originates from the dependence of $\mathbf{F}$ on the unknown $\mathbf{U}$. Changes of $\mathbf{U}$ lead to unpredictable changes of $\mathbf{F}$, making convergence difficult.

Newton-Raphson iterative scheme. This flaw is solved by application of the NewtonRaphson iterative scheme. Essentially, the system of non-linear equations (42) can be represented as:

$$
\mathrm{R}\left(\mathbf{U}^{\mathrm{t}+\Delta \mathrm{t}}\right)=0
$$

of which the root $\mathrm{U}^{t+\Delta t}$ has to be determined. The Newton-Raphson scheme states that:

$$
\mathbf{U}^{\mathrm{t}+\Delta \mathrm{t}, \mathrm{m}+1}-\mathbf{U}^{\mathrm{t}+\Delta \mathrm{t}, \mathrm{m}}=\Delta \mathbf{U}^{\mathrm{t}+\Delta \mathrm{t}, \mathrm{m}+1}=-\frac{\mathrm{R}\left(\mathbf{U}^{\mathrm{t}+\Delta \mathrm{t}, \mathrm{m}}\right)}{\frac{\partial \mathrm{R}}{\partial \mathbf{U}}\left(\mathbf{U}^{\mathrm{t}+\Delta t, \mathrm{~m}}\right)}
$$

Elaborating this for equation (43), the resulting equation to be solved is:

$$
\begin{gathered}
\left(\mathbf{C}^{\mathrm{t}+\Delta \mathrm{t}, \mathrm{m}}+\Delta \mathrm{t} \mathbf{K}^{\mathrm{t}+\Delta \mathrm{t}, \mathrm{m}}+\Delta \mathrm{t} \frac{\partial \mathbf{K}^{\mathrm{t}+\Delta \mathrm{t}, \mathrm{m}}}{\partial \mathbf{U}} \mathbf{U}^{\mathrm{t}+\Delta \mathrm{t}, \mathrm{m}}-\Delta \mathrm{t} \frac{\partial \mathbf{F}^{\mathrm{t}+\Delta \mathrm{t}, \mathrm{m}}}{\partial \mathbf{U}}\right) \Delta \mathbf{U}^{\mathrm{t}+\Delta \mathrm{t}, \mathrm{m}+\mathrm{l}}= \\
\Delta \mathrm{t} \mathbf{F}^{\mathrm{t}+\Delta \mathrm{t}, \mathrm{m}}-\Delta \mathrm{t} \mathbf{K}^{\mathrm{t}+\Delta \mathrm{t}, \mathrm{m}} \mathbf{U}^{\mathrm{t}+\Delta \mathrm{t}, \mathrm{m}}-\left(\mathbf{S}^{\mathrm{t}+\Delta \mathrm{t}, \mathrm{m}}-\mathbf{S}^{\mathrm{t}}\right)
\end{gathered}
$$

As can be seen in equation (45), the Newton-Raphson iterative scheme inserts "predictive information" on the changes of $\mathbf{F}-$ and of the material properties - with $\mathbf{U}$ in the left hand side coefficient matrix, seriously improving the convergence rate. The needed derivatives can all be calculated analytically. The efficiency of the scheme is illustrated in [12]. It is noteworthy that the Newton-Raphson elaboration of the conservative formulation yields a "slimmer" equation than that resulting from the original (35): among others, equation (45) does not contain derivatives of capacity matrices, implicitly enhancing the model's efficiency.

\subsection{Dynamic time stepping}

At the start of a rain shower very small time steps are desirable to allow accurate simulation of the absorption of precipitation by the external layer of the component. At other moments, larger time steps are preferable to reduce calculation time. For that reason a dynamic-time-step algorithm is developed. The size of the next time step is determined from the previous time step and the number of iterations performed during that step:

$$
\Delta \mathrm{t}^{\mathrm{i}+1}=\Delta \mathrm{t}^{\mathrm{i}} \min \left(\frac{\mathrm{m}_{\max }}{2 \mathrm{~m}}, 2\right)
$$

where $\Delta \mathrm{t}^{\mathrm{i}}$ and $\Delta \mathrm{t}^{\mathrm{i}+1}$ are the current and next time step (s) respectively, $\mathrm{m}$ the number of iterations needed to attain convergence in time step $\Delta \mathrm{t}^{\mathrm{i}}$, and $\mathrm{m}_{\max }$ is the maximum number of iterations allowed in one time step. The growth of the time step is not completely free: time step increases are limited to a factor 2 , as the lack of such an upper limit re- 
sults in frequent divergence of the numerical solution. The maximal time step is determined by the desired output frequency and the required transitions of the climate data values. When the iteration does not converge within $\mathrm{m}_{\max }$ iterations, the time step is halved and the iteration loop restarted.

\section{EXAMPLES}

The hygrothermal model is applied for two cases common in building physics: free water uptake by a building material, and atmospheric excitation of a building component. The negligible influence of oscillatory solutions - over- and undershoot at the toe of the moisture fronts - is illustrated for the free water uptake, the relevance of mass and energy conservative modelling on the other hand is illustrated for the atmospheric excitation. For all simulations, mass and energy conservative equations (42) are used with consistent capacity matrices (30.1-2), except where indicated. All simulations use ceramic brick as exemplary building material. Hygric properties are depicted in Figure 4, the thermal properties are: $\mathrm{c}_{0} \cdot \rho_{0}=840.2005 \mathrm{~J} / \mathrm{m}^{3} \mathrm{~K} ; \lambda=0.5+0.0045 \cdot \mathrm{w} \mathrm{W} / \mathrm{mK}$ [10]. As exemplary climate data, Design Reference Year data for Essen (Germany) are applied [22], containing values for the air temperature, direct and diffuse solar radiation, relative humidity, wind speed, wind direction and horizontal rain.

\subsection{Free water uptake by ceramic brick}

Free water uptake measurements are commonly carried out to determine the capillary moisture content and the capillary moisture absorption coefficient of building materials, two quantities required primarily in the determination of material properties. For such measurement, the underside of a beam-shaped sample is brought in contact with water, and the moisture accumulation in the sample is monitored. One-dimensional moisture transport is ensured by vapour tightening the vertical sides of the sample, and limiting the evaporation at the top of the sample. Theoretically the moisture accumulation should progress linearly with square root of time, and this proportionality is defined the capillary absorption coefficient $A_{\text {cap. }}$. This first example shows free water uptake by a 9 $\mathrm{cm}$ high ceramic brick sample. The initial and boundary conditions are:

$$
\begin{array}{lll}
\mathrm{t}<0 \mathrm{~s}: & \mathrm{x} \in[0 ; 0.09] \mathrm{m} & \mathrm{p}_{\mathrm{c}}=-10^{8} \mathrm{~Pa} \\
\mathrm{t} \geq 0 \mathrm{~s}: & \mathrm{x}=0 \mathrm{~m} & \mathrm{p}_{\mathrm{c}}=0 \mathrm{~Pa} \\
& \mathrm{x}=0.09 \mathrm{~m} & \mathrm{~g}_{\mathrm{m}}=0 \mathrm{~kg} / \mathrm{m}^{2} \mathrm{~s}
\end{array}
$$

Simulations are continued for $4500 \mathrm{~s}$, with alphanumeric output every $100 \mathrm{~s}$.

A first simulation employs a very fine 241-noded discretisation for the $9 \mathrm{~cm}$ sample: the resulting moisture content profiles and the accumulation of moisture are shown in Figure $5(a-b)$. The resultant $A_{\text {cap }}$ is $0.1411 \mathrm{~kg} / \mathrm{m}^{2} \mathrm{~s}^{0.5}$. As consistent capacity matrices are used (30.1), very small oscillations at the toe of the moisture fronts cannot be avoided. Far larger oscillatory behaviour at the moisture fronts' toe is obtained when a rough discretisation of 27 nodes [11] is used, as illustrated in Figure 5(c). As these oscillations mainly occur in the very dry range of the moisture retention curve, they do not yield any visible oscillations in the moisture content profiles in Figure 5(d). Application of lumped capacity matrices on the other hand yields non-oscillatory solutions. Figure 5 also indicates that the coarse discretisation results in a slight smearing of the capillary pressure and moisture content profiles, as was also noted in [46]. The resulting $A_{\text {cap }}$ remain very close to the original value though: $0.1409 \mathrm{~kg} / \mathrm{m}^{2} \mathrm{~s}^{0.5}$ and $0.1410 \mathrm{~kg} / \mathrm{m}^{2} \mathrm{~s}^{0.5}$ for the consistent and the lumped simulation respectively. The effect of maintaining mass distributed consistent capacity matrices (30.1) can thus be judged negligible.

\subsection{Atmospheric loading of ceramic brick outer leaf}

A second example illustrates the hygrothermal response of a $9 \mathrm{~cm}$ ceramic brick outer leaf of a cavity wall, exposed to the Essen climate. Only the outer leaf of the facade is simulated: the following insulation layer constitutes a hygric and thermal break, render- 
ing the hygric and thermal capacity of the inner leaf negligible for this simulation. Insulation and inner leaf are modelled with surface transfer coefficients of $10^{-10} \mathrm{~s} / \mathrm{m}$ and 0.7 $\mathrm{W} / \mathrm{m}^{2} \mathrm{~K}$, considering a nearly vapour tight, insulated structure. Orientation of the facade is South-West, close to the SW-W primary Essen wind-driven rain direction, and winddriven rain coefficients for the top corner of the small cubic building are applied. The initial conditions remain (47), the boundary conditions are atmospheric excitation (7-24). The simulations are continued for 70 days, with an alphanumerical output every hour. Only the first 70 days of the year are used here, as the related climate conditions yield a complete build-up from dryness to saturation and back down again. Figure 6(a) depicts the resulting variation of the average and external surface moisture content. To illustrate the relevance of mass and energy conservative modelling, and the negligible effect of the fully implicit temporal discretisation, the simulation is repeated with maximal time steps of $0.36,36$ and $3600 \mathrm{~s}$, and with non-conservative transfer equations. The results, limited to the average moisture contents in the brick outer leaf, are shown in Figure 6(b). Both $0.36 \mathrm{~s}$ simulations, conservative and not, yield similar results, indicating the equivalency of (35) and (42) for short time steps: the variation of $p_{c}$ and thus $\partial w / \partial p_{c}$ during a short time step is practically nihil, making any conservative corrections redundant. The deviations between the $36 \mathrm{~s}$ and $3600 \mathrm{~s}$ conservative and non-conservative simulations express the need for conservative modelling however: while the conservative $36 \mathrm{~s}$ and $3600 \mathrm{~s}$ results do not show any digression from the $0.36 \mathrm{~s}$ result, the non-conservative $36 \mathrm{~s}$ and $3600 \mathrm{~s}$ simulations reveal serious deviations, growing larger with larger time steps.

The agreement between the three conservative simulations also demonstrates the negligible effect of the fully implicit temporal discretisation: while all material properties and boundary conditions are calculated based on the final capillary pressures and temperatures (35) - instead of the initial (explicit) or intermediate values (Crank-Nicholson) -, this does not significantly affect the simulation results: the 3600 s results do not deviate from the reference $0.36 \mathrm{~s}$ results.

\section{Conclusions}

This paper comprehensively presented a numerical model for simulations of moisture and heat transfer in building components under atmospheric excitation. A first section of the paper introduced transfer equations and atmospheric boundary conditions, with an emphasis on wind-driven rain and vapour exchange, respectively the key moisture supply and removal mechanism for permeable building components [13]. Whereas a comprehensive calculation method - incorporating the influence of building geometry, environment topography, position on the building, wind speed, wind direction, horizontal rainfall and raindrop-size distribution - exists for the wind-driven rain coefficients $\alpha$, this is not so for the surface transfer coefficients. Only a few of the influencing factors are integrated in the currently proposed methodology. Refinement is required, and further research on this matter is strongly encouraged.

A second section presented the numerical modelling of transfer equations and boundary conditions, with an accent on mass and energy conservative modelling. It was verified that the common temporal discretisation of non-linear equations may yield conservation errors, which can be solved by starting from the mixed transfer equation form. Since this conservative modelling was developed independently of the spatial discretisation method, it can be generally applied, in finite-element, finite-difference and control-volume methods. It was moreover indicated that mass lumping, a commonly applied technique to avoid oscillations at the toe of moisture fronts in finite elements, may not be generally valid. After verifying that the effect of such oscillations is limited it was decided to maintain the original consistent formulations for the capacity matrices.

This paper contributes two important matters to the currently ongoing standardisation of the numerical simulation of moisture transfer in building components [9] and its re- 
lated quality assessment methodology [10]: the atmospherical boundary conditions, and the mass and energy conservative modelling. The efficient numerical solution of the resulting system of equations, while already introduced in this paper, is further elaborated in $[11,12]$.

\section{ACKNOWLEDGEMENT}

The results presented in this paper have been obtained within the frame of the SBO IWT 03175 project 'Structural damage due to dynamic excitations: a multi-disciplinary approach', funded by 'IWT Vlaanderen', the Institute for the Promotion of Innovation by Science and Technology in Flanders. The second author is a postdoctoral fellow funded by the FWO-Flanders (Research Fund Flanders). This financial support is gratefully acknowledged. The reviewer who supplied reference [37] is kindly thanked.

\section{REFERENCES}

[1] EN 13788: Hygrothermal performance of building components and building elements - Internal surface temperature to avoid critical surface humidity and interstitial condensation - Calculation methods.

[2] Holm A, Künzel HM, Two-dimensional transient heat and moisture simulations of rising damp with WUFI2D, in: Carmeliet, Hens, Vermeir (ed.), Proceedings of the $2^{\text {nd }}$ International Conference on Building Physics, Leuven, Belgium, 2003, pp. 363-367.

[3] Mukhopadhyaya P, Kumaran K, Rousseau M, Tariku F, Van Reenen D, Application of hygrothermal analyses to optimise exterior wall design, in: Carmeliet, Hens, Vermeir (ed.), Proceedings of the $2^{\text {nd }}$ International Conference on Building Physics, Leuven, Belgium, 2003, pp. 417-426.

[4] Scheffler G, Grunewald J, Interior capillary-active thermal insulation: a material development study, Building Research Journal 50 (2002) 153-168.

[5] Zillig W, Lenz K, Sedlbauer K, Krus M, Condensation on facades - influence of construction type and orientation, in: Carmeliet, Hens, Vermeir (ed.), Proceedings of the $2^{\text {nd }}$ International Conference on Building Physics, Leuven, Belgium, 2003, pp. 437-444.

[6] Sedlbauer K, Prediction of mould growth by hygrothermal calculation, Journal of Thermal Envelope and Building Science 25 (2002) 321-336.

[7] Blocken $B$, Janssen $\mathrm{H}$, Carmeliet $\mathrm{J}$, On the modelling of runoff of driving rain on a capillary active surface, in: Haupl, Roloff (ed.), Proceedings of the $11^{\text {th }}$ Symposium of Building Physics, Dresden, Germany, 2002, pp. 400-408.

[8] Simonson CJ, Salonvaara M, Ojanen T, Heat and mass transfer between indoor air and a permeable and hygroscopic building envelope : part II - verification and numerical studies, Journal of Thermal Envelope and Building Science 28 (2002) 161-185.

[9] CEN/TC89 WG10: Hygrothermal performance of building components and building elements - Assessment of moisture transfer by numerical simulation (prenormative text), 2003.

[10] Hagentoft C-E, Kalagasidis AS, Adl-Zarrabi B, Roels S, Carmeliet C, Hens H, Grunewald J, Funk M, Becker R, Shamir D, Adan O, Brocken H, Kumaran K, Djebbar R, Assessment method of numerical prediction models for combined heat, air and moisture transfer in building components: benchmarks for onedimensional cases, Journal of Thermal Envelope and Building Science 27 (2004), 327-352.

[11] Janssen $\mathrm{H}$, Carmeliet $\mathrm{C}$, Two-rank numerical integration in simulation of moisture transfer in porous materials, Communications in Numerical Methods in Engineering (2006), submitted for publication.

[12] Janssen H, Carmeliet C, Variations on Newton-Raphson in simulation of moisture 
transfer in porous materials, Communications in Numerical Methods in Engineering (2006), submitted for publication.

[13] Janssen H, Blocken B, Roels S, Carmeliet J, Wind-driven rain as a boundary condition for HAM simulations: analysis of simplified modelling approaches. Building and Environment (2005), accepted for publication.

[14] Whitaker S, Simultaneous heat, mass and momentum transfer in porous media: a theory of drying, Advances in Heat Transfer 13 (1977) 119-203.

[15] Gray WG, General conservation equations for multi-phase systems, 4, constitutive theory including phase change, Advances in Water Resources 6 (1983) 130140.

[16] Philip JR, de Vries DA, Moisture movement in porous materials under temperature gradients, Transactions American Geophysical Union 38 (1957) 222-232.

[17] Taylor SA, Cary JW, Linear equations for the simultaneous flow of water and energy in a continuous soil system, Soil Science Society of America Proceedings 28 (1964) 167-172.

[18] Luikov AV, Heat and mass transfer in capillary-porous bodies, Pergamonn Press, London, 1966.

[19] Hens H, IEA Annex 24 Final Report Volume 1: Modelling, Acco Leuven, Belgium, 1996.

[20] Pedersen CR, Combined heat and moisture transfer in building constructions, PhD thesis, Technical University of Denmark, Denmark, 1990.

[21] Künzl H, Verfahren zur ein- und zweidimensionalen Berechnung des gekoppeltes Wärme- und Feuchtestransports in Bauteilen mit einfachen Kennwerten, PhD thesis, University of Stuttgart, Germany, 1994.

[22] Grunewald J, Diffusiver und konvektiver Stoff- und Energietransport in kapillarporösen Baustoffen, PhD thesis, Tecnische Universität Dresden, Germany, 1997.

[23] Kittler R, A universal calculation method for simple predetermination of natural radiation on building surfaces and solar collectors. Building and Environment 16 (1981) 177-182.

[24] Janssen $\mathrm{H}$, The influence of soil moisture transfer on building heat loss via the ground, PhD thesis, Katholieke Universiteit Leuven, Belgium, 2002.

[25] Janssen $\mathrm{H}$, Carmeliet $\mathrm{J}$, Hens $\mathrm{H}$, The influence of soil moisture transfer on building heat loss via the ground, Building and Environment 39 (2004) 825-836.

[26] Kasten F, Czeplak G, Solar and terrestrial radiation dependent on the amount and type of cloud, Solar Energy 24 (1980) 177-189.

[27] Bishop JKB, Rossow WB, Spatial and temporal variability of global surface solar irradiance, Journal of Geophysical Research 96 (1991) 16839-16858.

[28] Blocken B, Carmeliet J, A review of wind-driven rain research in building science, Journal of Wind Engineering and Industrial Aerodynamics 92 (2004) 1079-1130.

[29] Blocken B, Carmeliet J, Spatial and temporal distribution of driving rain on a lowrise building, Wind \& Structures 5 (2002) 441-462.

[30] Blocken B, Carmeliet J, The influence of the wind blocking effect by a building on its wind-driven rain exposure, Journal of Wind Engineering and Industrial Aerodynamics 94 (2006) 101-127.

[31] Worch A, The behaviour of vapour transfer on building material surfaces: the vapour transfer resistance, Journal of Thermal Envelope and Building Science 28 (2004) 187-199.

[32] Wads $\varnothing$ L, Surface mass transfer coefficients for wood, Drying Technology 11 (2003) 1227-1249.

[33] McAdams WH, Heat transmission, $3^{\text {rd }}$ ed. McGraw-Hill, New York, 1954.

[34] Ito N, Kimura K, Oka J, A field experiment study on the convective heat transfer coefficient on the exterior surface of a building, Ashrae Transactions 78 (1972), 184-191. 
[35] Sharples S, Full scale measurements of convective energy losses from exterior building surfaces, Building and Environment 19 (1984) 31-39.

[36] Loveday DL, Taki AH, Convective heat transfer coefficients at a plane surface on a full-scale building facade, International Journal for Heat and Mass transfer 39 (1996) 1729-1742.

[37] Schwarz B, Die Wärme- und Stoffübertragung an Außenoberflächen, Berichte aus der Bauforschung, 79, Wilhelm Ernst \& Sohn, Berlin, 1971.

[38] Geving S, Averaging of climatic data and its effect on moisture transfer calculations. IEA Annex 24, report T2-N-94/04, 1994.

[39] Blocken B, Roels S, Carmeliet J, A combined CFD-HAM approach for winddriven rain on building facades, Journal of Wind Engineering and Industrial Aerodynamics (2005) submitted for publication.

[40] Kalagasidis AS, Bednar T, Hagentoft CE, Evaluation of the interface moisture conductivity between control volumes - comparison between linear, harmonic and integral averaging, in: Ashrae (ed.), Proceedings of the Performance of Exterior Envelopes of Whole Buildings IX International Conference, Clearwater Beach, Florida, 2004.

[41] Patankar SV, Numerical heat transfer and fluid flow, Hemisphere Publishing Corporation, New York, 1980.

[42] Van Genuchten MT, A comparison of numerical solutions of the one-dimensional unsaturated-saturated flow and mass transport equations, Advances in Water Resources 5 (1982) 47-55.

[43] Neuman SP, Saturated-unsaturated seepage by finite elements, Journal of the Hydraulics Division of the American Society of Civil Engineers 99 (1973) 22332250.

[44] Milly PCD, A mass-conservative procedure for time-stepping in models of unsaturated flow, Advances in Water Resources 8 (1985) 32-36.

[45] Rathfelder K, Abriola LM, Mass conservative numerical solutions for the headbased Richards equation, Water Resources Research 30 (1994) 2579-2586.

[46] Celia MA, Bouloutas ET, Zarba RL, A general mass-conservative numerical solution for the unsaturated flow equation, Water Resources Research 26 (1990) 1483-1496.

[47] Pan L, Warrick AW, Wierenga PJ, Finite element methods for modeling water flow in variably saturated porous media: Numerical oscillation and massdistributed schemes, Water Resources Research 32 (1996)1883-1889.

[48] Reddy JN, Gartling DK, The finite element method in heat transfer and fluid dynamics (second edition), CRC Press, Boca Raton, 2001. 


\section{FIGURE CAPTIONS}

Figure 1: Wind-driven rain coefficients $\alpha_{\perp}\left(R_{h}, U^{\prime}\right)\left(R_{h}\right.$ and $R_{w d r}$ in $\left.\mathrm{kg} / \mathrm{m}^{2} h\right)$ for the left top corner (a), centre (b), of a cubic $\left(10 \times 10 \times 10 \mathrm{~m}^{3}\right)$ building's facade.

Figure 2: comparison of different relations between average surface heat transfer coefficient and reference wind speed (full curves: windward side, dashed curves: leeward side).

Figure 3: illustration of moisture storage for the mixed (40) and $p_{c}$-based (41) isothermal moisture transfer equation.

Figure 4: moisture retention curve (a), liquid and vapour permeability (b), for ceramic brick at $293.15 \mathrm{~K}$.

Figure 5: moisture content profiles at 500, 1500, 2500, 3500, $4500 \mathrm{~s}(\mathrm{a})$, moisture accumulation over time (b), capillary pressure profiles at $1500 \mathrm{~s}$ (c), moisture content profiles at $1500 \mathrm{~s}(\mathrm{~d})$, during free water uptake by $9 \mathrm{~cm}$ ceramic brick.

Figure 6: average and external surface moisture contents from a conservative simulation (a), average moisture contents from conservative and non-conservative simulations with maximal time steps of $0.36,36$ and $3600 \mathrm{~s}$ (b), for 70-day atmospheric excitation of $9 \mathrm{~cm}$ ceramic brick outer leaf. 


\section{FIGURE 1:}
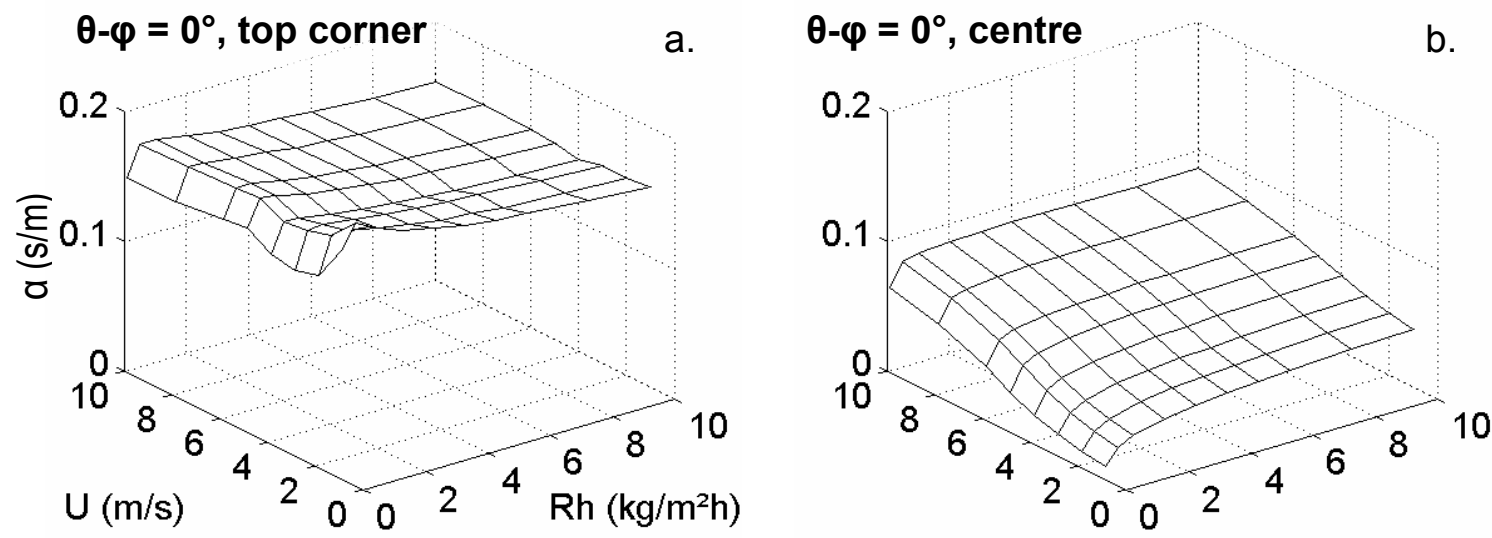

FIGURE 2:

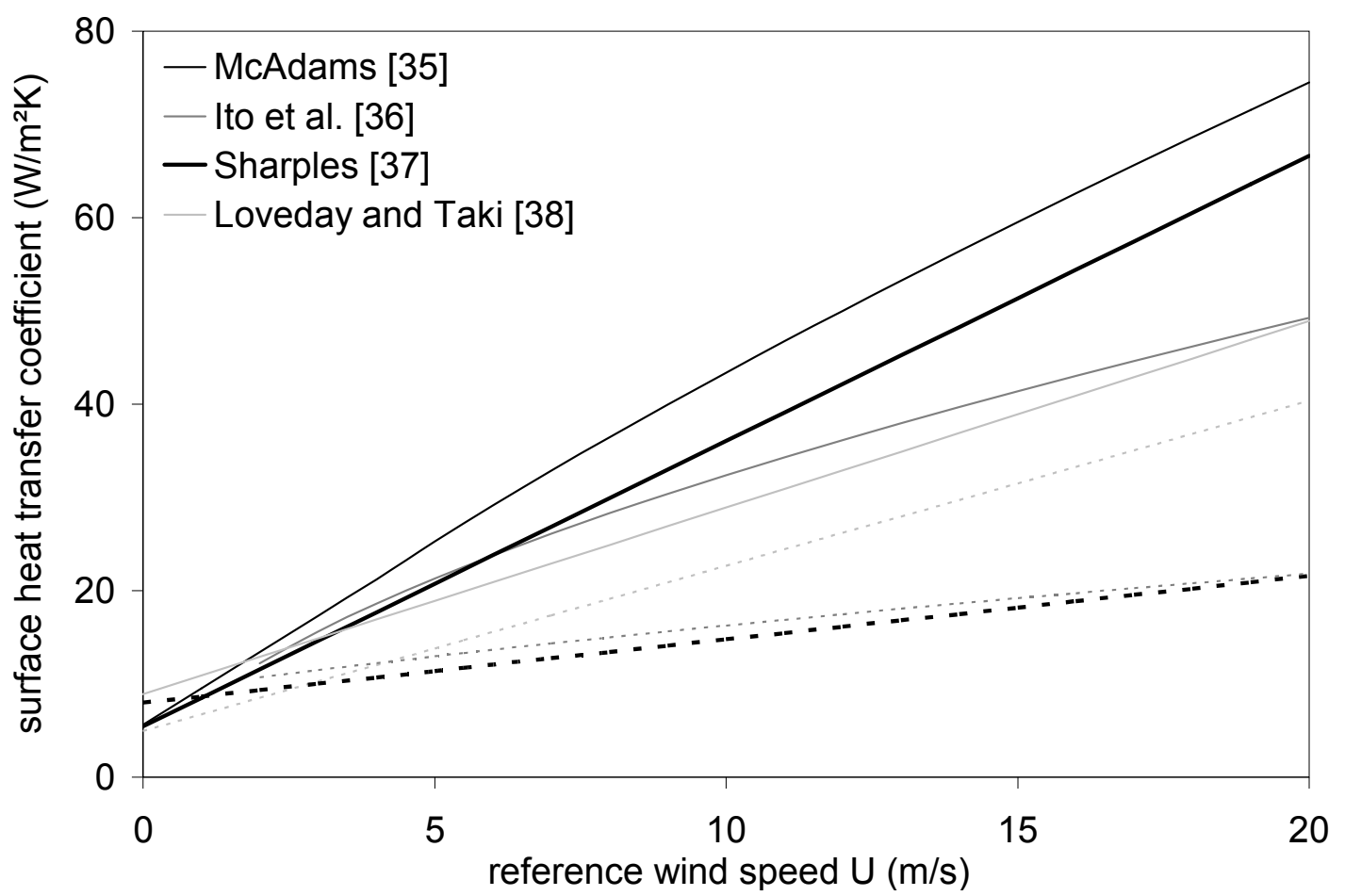


FIGURE 3:

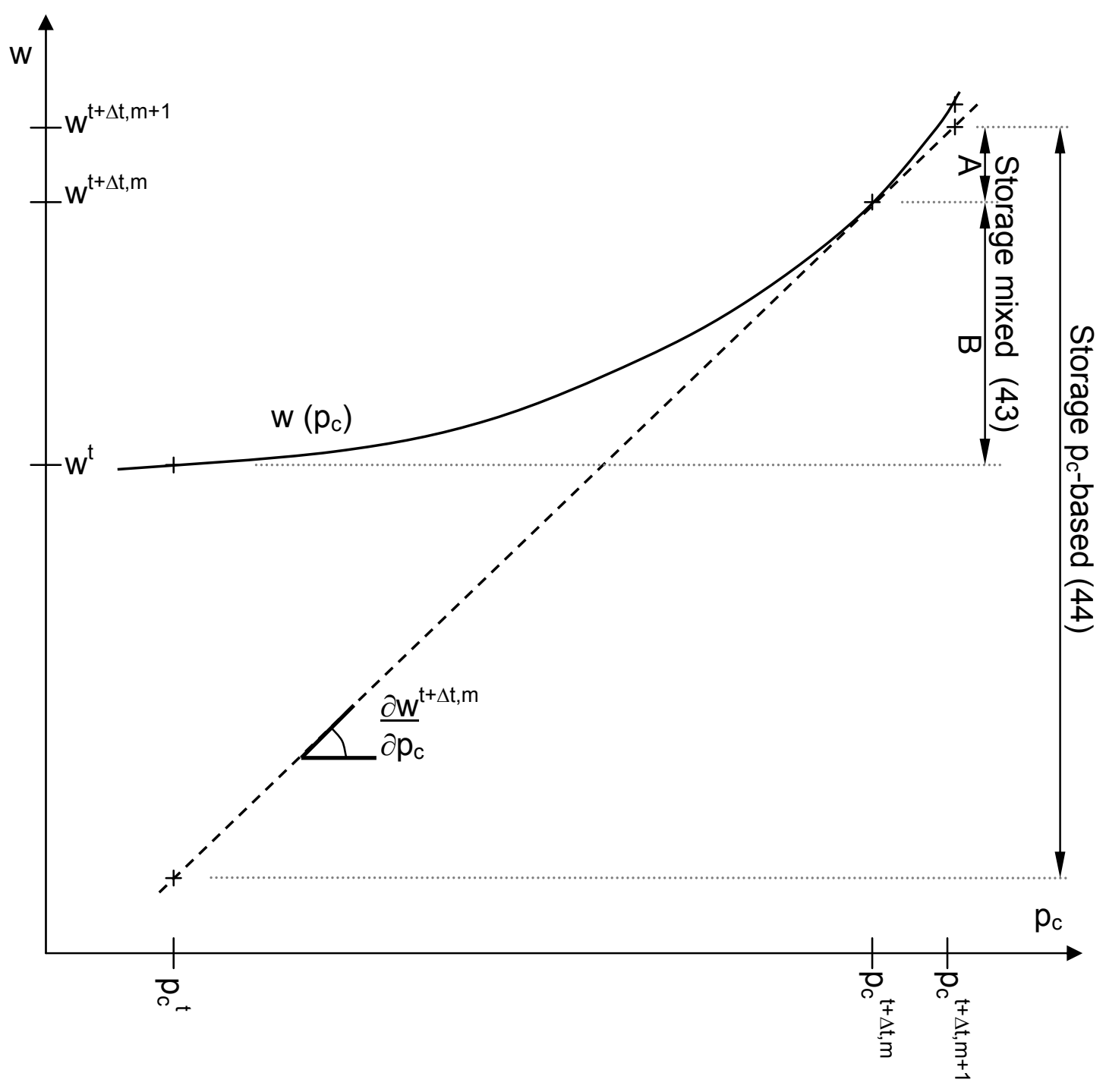

FIGURE 4:
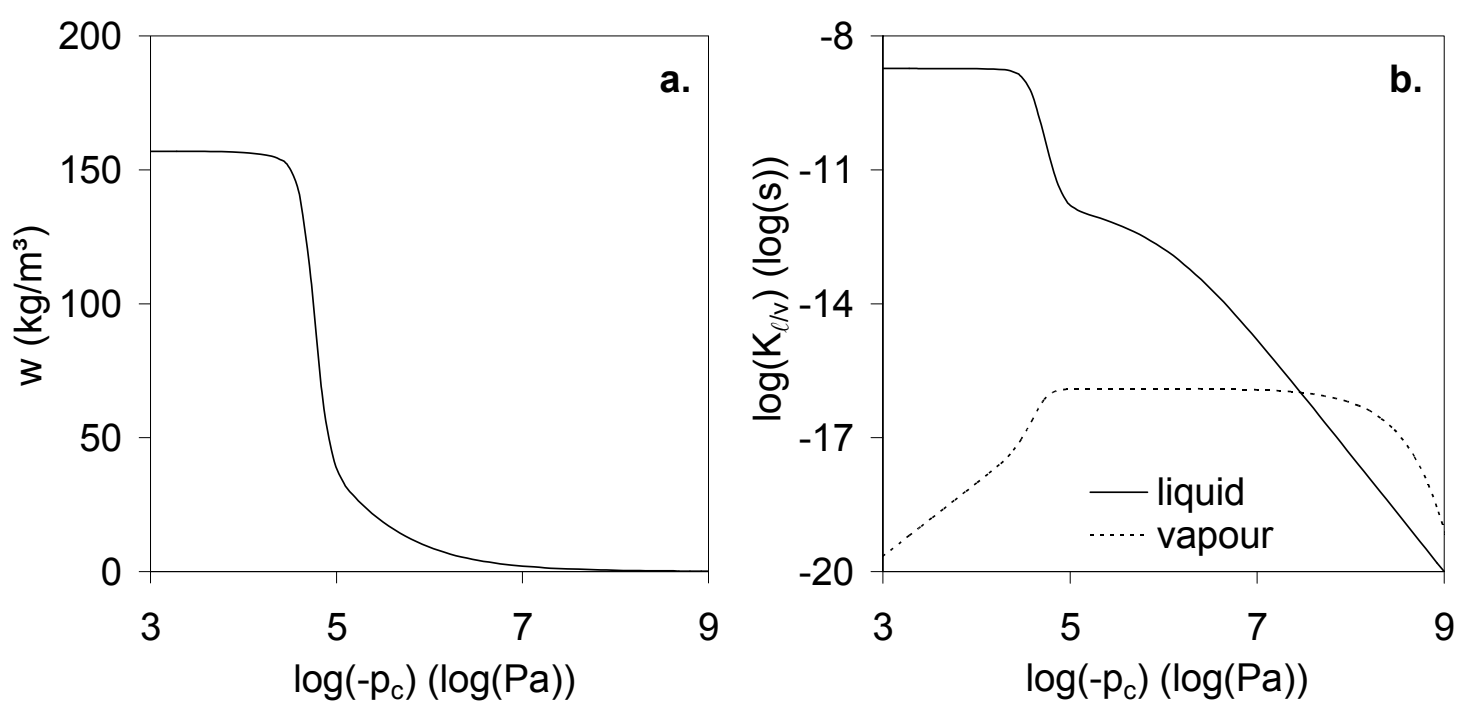
FIGURE 5:
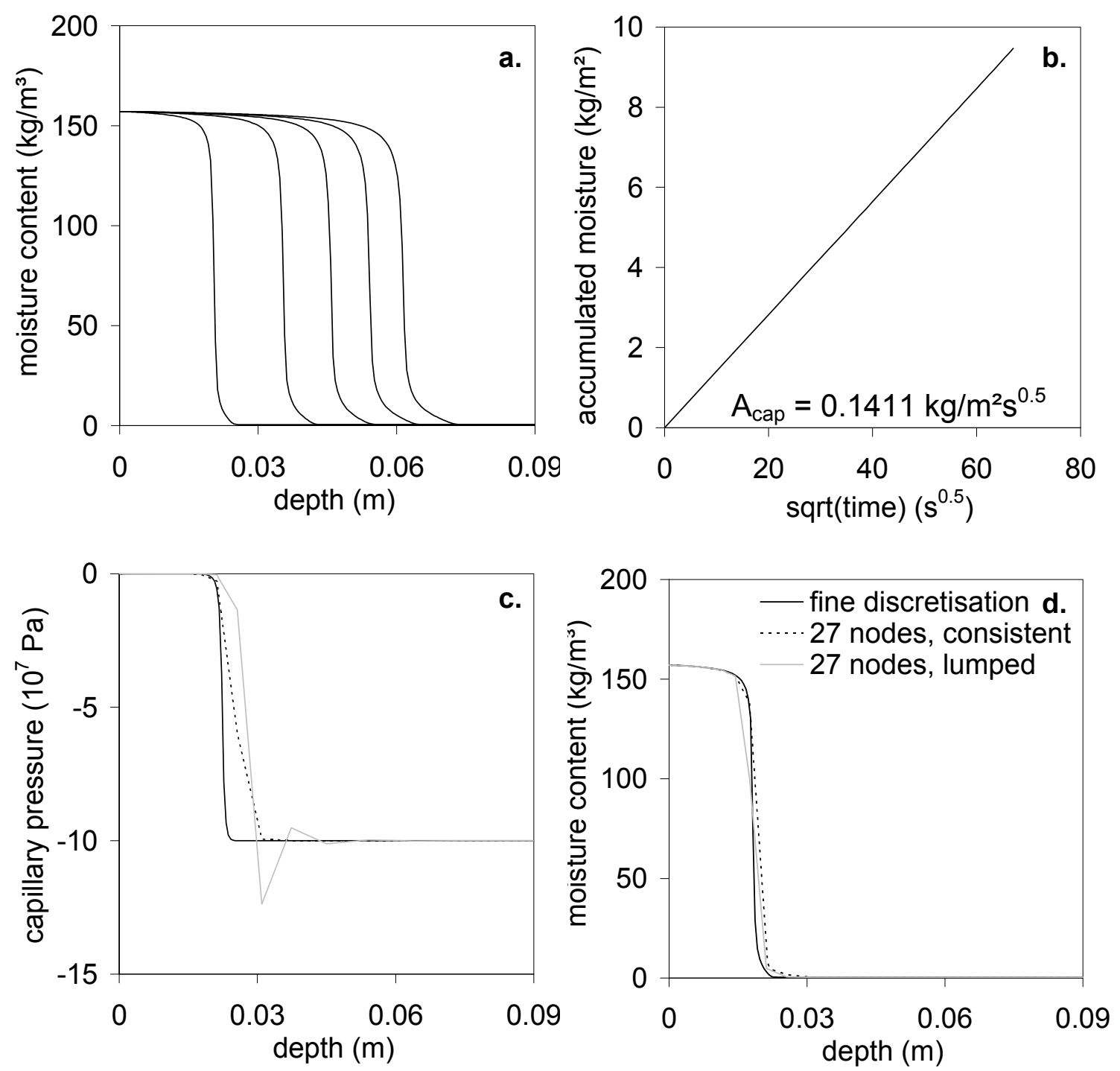
FIGURE 6:
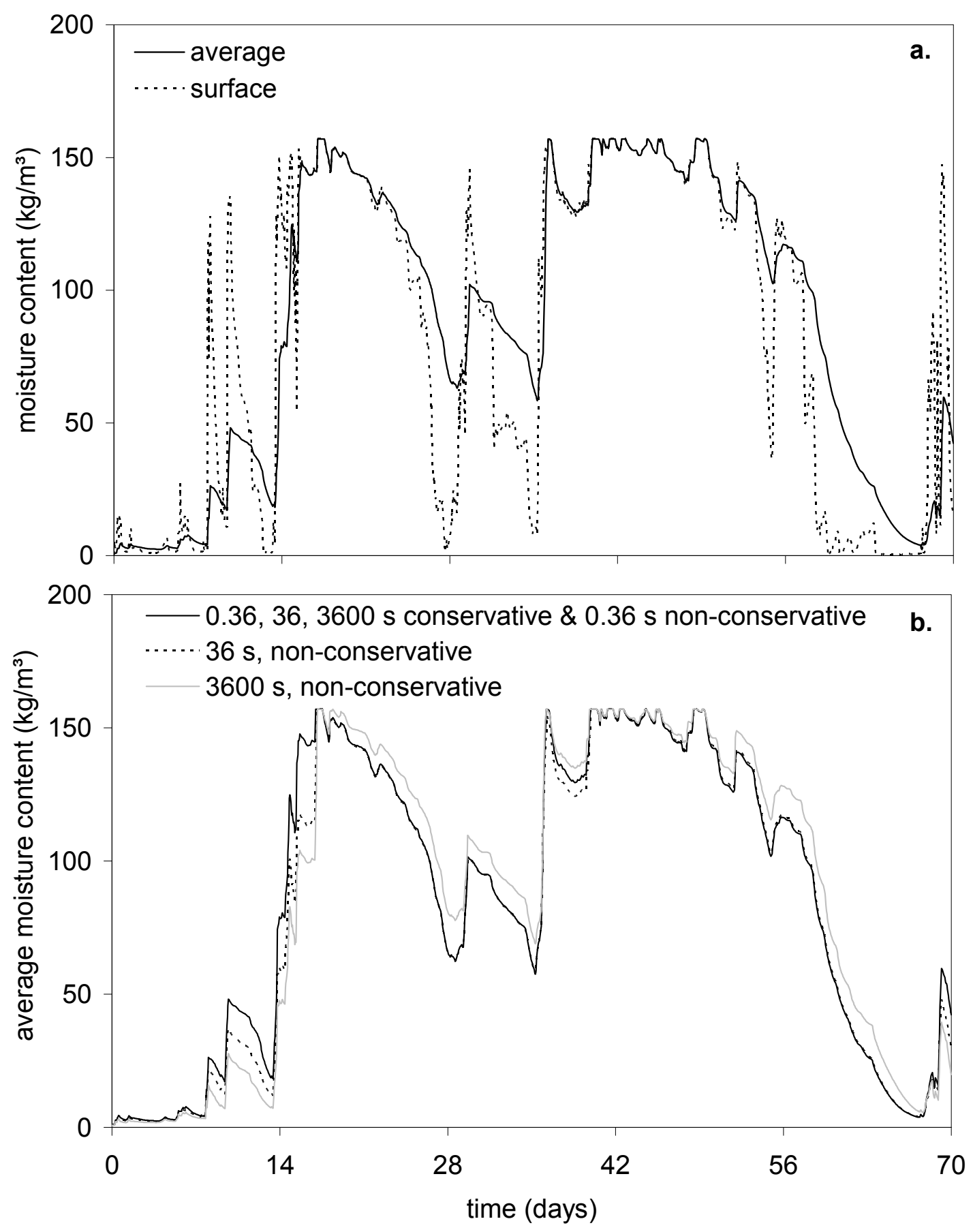